Digital Computer Control Systems 


\section{Macmillan New Electronic Series}

Series Editor: Paul A. Lynn

Rodney F. W. Coates, Underwater Acoustic Systems

W. Forsythe and R. M. Goodall, Digital Control

Paul A. Lynn, Radar Systems

A. F. Murray and H. M. Reekie, Integrated Circuit Design

F. J. Owens, Signal Processing of Speech

Dennis N. Pim, Television and Teletext

M. J. N. Sibley, Optical Communications

Martin S. Smith, Introduction to Antennas

P. M. Taylor, Robotic Control

G. S. Virk, Digital Computer Control Systems

Allan Waters, Active Filter Design

\section{Series Standing Order}

If you would like to receive further titles in this series as they are published, you can make use of our standing order facility. To place a standing order please contact your bookseller or, in case of difficulty, write to us at the address below with your name and address and the name of the series. Please state with which title you wish to begin your standing order. (If you live outside the United Kingdom we may not have the rights for your area, in which case we will forward your order to the publisher concerned.)

Customer Services Department, Macmillan Distribution Ltd Houndmills, Basingstoke, Hampshire, RG21 2XS, England. 


\title{
Digital Computer Control Systems
}

\author{
G. S. Virk \\ Department of Control Engineering \\ University of Sheffield
}

Macmillan New Electronics

Introductions to Advanced Topics

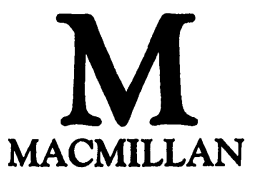


All rights reserved. No reproduction, copy or transmission of this publication may be made without written permission.

No paragraph of this publication may be reproduced, copied or transmitted save with written permission or in accordance with the provisions of the Copyright, Designs and Patents Act 1988 , or under the terms of any licence permitting limited copying issued by the Copyright Licensing Agency, 33-4 Alfred Place, London WC1E 7DP.

Any person who does any unauthorised act in relation to this publication may be liable to criminal prosecution and civil claims for damages.

First edition 1991

Published by

MACMILLAN EDUCATION LTD

Houndmills, Basingstoke, Hampshire RG21 2XS

and London

Companies and representatives

throughout the world

British Library Cataloguing in Publication Data

Virk, G.S.

Digital computer control systems. - (Macmillan new electronics).

I. Title. II. Series.

621.382

ISBN 978-0-333-51405-4

ISBN 978-1-349-21490-7 (eBook)

DOI 10.1007/978-1-349-21490-7 
To Ann, Bernadette and Térese, and to the memory of my Father. 


\section{Contents}

Series Editor's Foreword $\quad$ xi

Preface $\quad$ xii

1 Computers in Control Systems 1

1.1 Introduction . . . . . . . . . . . . . . 1

1.2 Historical Development . . . . . . . . . . . . . 3

1.3 Digital Computer Interfacing . . . . . . . . . . . 5

Structure of a Digital Control Loop . . . . . . . . . . . 6

Interface Units . . . . . . . . . . . . . . . 7

Data Representation and Aliasing . . . . . . . . . . . 12

1.4 Summary .................... . . 15

2 The $z$-Transformation $\quad 17$

2.1 Introduction . . . . . . . . . . . . . . . . . 17

2.2 Definition of the $z$-Transform . . . . . . . . . . . . . 18

$2.3 z$-Transform Properties . . . . . . . . . . . . . . . . . . . . . 19

2.4 Inverse $z$-Transform . . . . . . . . . . . . . . . . 20

2.5 Pulse or $z$-Transfer Functions of Systems . . . . . . . . . 23

2.6 Discrete Approximations . . . . . . . . . . . . . 26

Numerical Integration . . . . . . . . . . . . . . 26

Pole-Zero Mapping . . . . . . . . . . . . . . . . . . 29

2.7 Modified $z$-Transform . . . . . . . . . . . . . . 31

2.8 Multi-rate Sampling Systems . . . . . . . . . . . . . 36

Analysis of Multi-rate Systems . . . . . . . . . . . 36

Slow-Fast Multi-rate Systems . . . . . . . . . . . . . 37

Fast-Slow Multi-rate Systems . . . . . . . . . . . . . 37

All Digital Element Multi-rate Systems . . . . . . . . . . 38

Closed-loop Multi-rate Systems . . . . . . . . . . 39 
2.9 Summary . . . . . . . . . . . . . . . 40 40

2.10 Problems .................... . 40

3 Analysis of Sampled-Data Control Systems 43

3.1 Introduction . . . . . . . . . . . . . . . 43

$3.2 z$-Transformation of Systems _ . . . . . . . . . . 43

Systems with Samplers in Cascade . . . . . . . . . . . 43

Systems in Cascade without Separating Samplers . . . . . . . 44

Closed-Loop Systems . . . . . . . . . . . . . . . . . . 45

3.3 Stability in Discrete Systems _ . . . . . . . . . . . . 47

Stability Boundary . . . . . . . . . . . . . . . 47

Routh's Method ................. 50

Jury's Method . . . . . . . . . . . . . . . . 52

Raible's Method . . . . . . . . . . . . . . . 54

Singular Cases . . . . . . . . . . . . . . . 55

3.4 Time Domain Analysis . . . . . . . . . . . . . . . . . 57

3.5 Root Locus Analysis . . . . . . . . . . . . . . . . . 58

Constant Damping Ratio Loci in the $z$-plane . . . . . . . 60

Rise-time Considerations . . . . . . . . . . . . . . . . 6 60

Settling Time Considerations . . . . . . . . . . . . . 62

3.6 Frequency Domain Analysis . . . . . . . . . . . . . . . 64

Approximate Frequency Domain Analysis . . . . . . . . 66

3.7 Summary . . . . . . . . . . . . . . . 6 69

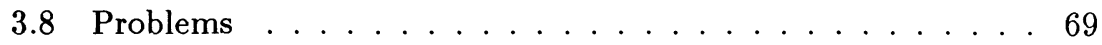

4 Digital Compensator Design $\quad 72$

4.1 Introduction . . . . . . . . . . . . . . . . 72

4.2 Continuous Domain Design _ . . . . . . . . . . 75

4.3 Digital Design . . . . . . . . . . . . . . . . . . 80

4.4 Digital Root Locus Design . . . . . . . . . . . . . . . . 83

4.5 State Feedback Design . . . . . . . . . . . . . . . 86

State Feedback in Servo Systems . . . . . . . . . . . . 90

State Observers . . . . . . . . . . . . . . . . . . . 93

4.6 Digital PID Control Design . . . . . . . . . . . . 96

Closed-loop Methods . . . . . . . . . . . . . . . . . . . . 99

Open-loop Method . . . . . . . . . . . . . . . . . . . . . 99

4.7 Deadbeat Response Design . . . . . . . . . . . . . . 104

4.8 Optimal Control Design . . . . . . . . . . . . . . . . 106

4.9 Controller Design in the Presence of Noise . . . . . . . . . . 112

4.10 Summary . . . . . . . . . . . . . . . . 115

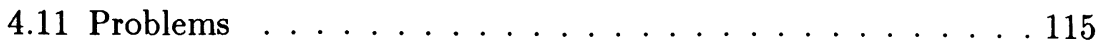


5 Real-Time Computer Control Systems 122

5.1 Introduction . . . . . . . . . . . . . . . . . 122

5.2 Hardware Requirements . . . . . . . . . . . . . . 124

The Digital Computer and Peripheral Equipment . . . . . . . 124

The Real-Time Clock . . . . . . . . . . . . . . . 126

Interface Units . . . . . . . . . . . . . . . . . . 127

5.3 Software Aspects . . . . . . . . . . . . . . . . 128

Controller Implementation . . . . . . . . . . . . . . 128

Programming Languages . . . . . . . . . . . . . . . . 130

5.4 System Design Co-ordination . . . . . . . . . . . . . . . 131

Sampling Rate Selection and Quantisation Errors . . . . . . 132

Computer/Device Communications . . . . . . . . . . . 133

Interrupt Handling . . . . . . . . . . . . . . . . . . 134

Multi-tasking and Background/Foreground . . . . . . . . 134

5.5 Summary . . . . . . . . . . . . . . . 135

6 Advances in Computer Control 136

6.1 Introduction . . . . . . . . . . . . . . . 136

6.2 Artificial Intelligence . . . . . . . . . . . . . . . . 137

Expert Systems . . . . . . . . . . . . . . . . 137

Examples of Expert Systems _. . . . . . . . . . . . . 139

6.3 Knowledge-Based Systems in Control Engineering . . . . . 141

Conventional Controller Design Methods . . . . . . . . . . . . 142

Manual Control Methods . . . . . . . . . . . . . . . . . . 142

6.4 Fuzzy Sets and Rule-Based Control . . . . . . . . . . . . . 143

Basic Fuzzy Operations . . . . . . . . . . . . . . . . 144

Fuzzy Relations . . . . . . . . . . . . . . . . . . . . 147

Fuzzy Control Algorithms . . . . . . . . . . . . . 151

6.5 Parallel Processing Techniques . . . . . . . . . . . 153

Parallel Computers . . . . . . . . . . . . . . . . . . . 154

Algorithms for Parallel (MIMD) Computers . . . . . . . . 158

Programming Parallel Computers . . . . . . . . . . . . . . . 159

Performance of Parallel Computers . . . . . . . . . . . . 160

6.6 Parallel Processing in Control Engineering . . . . . . . . . . 161

Matrix Algebra . . . . . . . . . . . . . . . . . . . . . 163

Numerical Integration . . . . . . . . . . . . . . . 164

Fault Tolerance . . . . . . . . . . . . . . . . 166

6.7 Summary . . . . . . . . . . . . . . . . . . . 168 
$\begin{array}{lr}\text { Bibliography and References } & 169\end{array}$

$\begin{array}{lr}\text { Appendixes } & 176\end{array}$

A: Table of Laplace and $z$-Transforms $\quad 176$

$\begin{array}{lr}\text { B: Continuous Second-order Systems } & 178\end{array}$

B.1 Introduction . . . . . . . . . . . . . . . . . . 178

B.2 Response Specifications . . . . . . . . . . . . . . . 178

B.3 Frequency Response Characteristics . . . . . . . . . . . . . . 182

C: The Transputer and occam 184

C.1 Introduction . . . . . . . . . . . . . . . . . . . . 184

C.2 occam Overview . . . . . . . . . . . . . . . . 185

C.3 Transputer Systems and occam Configuration . . . . . . . . 188

C.4 Vibration Control of a Flexible Cantilever . . . . . . . . . . . 190

System Simulation . . . . . . . . . . . . . . . . . 196

Modelling and State Estimation . . . . . . . . . . . . . 197

Controller Design . . . . . . . . . . . . . . . . . . . . . . . 198

User Interface . . . . . . . . . . . . . . . . . . . . . . 199

$\begin{array}{lr}\text { D: Solutions to Problems } & \mathbf{2 0 0}\end{array}$

$\begin{array}{lr}\text { Index } & \mathbf{2 1 3}\end{array}$ 


\section{Series Editor's Foreword}

The rapid development of electronics and its engineering applications ensures that new topics are always competing for a place in university and polytechnic courses. But it is often difficult for lecturers to find suitable books for recommendation to students, particularly when a topic is covered by a short lecture module, or as an "option".

Macmillan New Electronics offers introductions to advanced topics. The level is generally that of second and subsequent years of undergraduate courses in electronic and electrical engineering, computer science and physics. Some of the authors will paint with a broad brush; others will concentrate on a narrower topic, and cover it in greater detail. But in all cases the titles in the Series will provide a sound basis for further reading in the specialist literature, and an up-to-date appreciation of practical applications and likely trends.

The level, scope and approach of the Series should also appeal to practising engineers and scientists encountering an area of electronics for the first time, or needing a rapid and authoritative update.

Paul A. Lynn 


\section{Preface}

Digital control methods are replacing most conventional analogue systems. It is therefore important that the control engineers of the present and future are familiar with the features and facilities available, and are aware of the limitations of such systems. The aim of the book is to present an up-to-date introduction to these systems, and to instruct and assist readers so that they are able to connect digital computers to real systems for control and/or analysis purposes. The main aspects such as discretisation and system design methodologies which need to be considered for solving a particular application are discussed so that the reader is able to successfully perform a complete system design for his/her problem.

The material assumes that readers have completed a first course in control systems where the classical continuous domain methods have been covered, as well as some of the concepts of the state-space approach. Hence knowledge of such areas as the Laplace transform, frequency (Bode, Nyquist, Nichol, etc.), and time domain analysis methods, root locus, compensator design, etc., is assumed. These methods are extended to the discrete $z$ domain so that computer control can be implemented. Both input/output (classical control) and state-space (modern control) methods are presented with application to illustrative examples. At the end of some of the chapters, numerical problems are included with sample solutions provided in an appendix.

It is not the intention to concentrate on one particular application area but to present an overall systems design approach, so that the generic control methods can be applied to a variety of different areas. Hence the book should be of interest to third year undergraduate or master's students in all branches of engineering and applied mathematics as well as practising engineers and scientists.

The book chapters are set out as follows. The first chapter gives a historical perspective on computer control, and considers aspects such as interfacing (A/D and D/A converters), sampling rates, quantisation effects, hold devices and the problems caused by aliasing. In chapter 2 the $z$-transform and its properties are introduced, and how it is used in studying digital processes and systems. Discrete approximations can simplify the analysis 
greatly and are therefore considered in some detail. Since the $z$-transform analysis can only define the time responses at the discrete sampling instants, the modified $z$-transform is also presented so that inter-sampling time values can be described. In addition, the usefulness of multi-rate sampling is discussed so that computer resources can be optimised and appropriate sample rates used to maximise the effectiveness.

Chapter 3 considers the study of systems in the $z$-domain. The stability methods of Routh, Jury and Raible for sampled-data systems are presented and how time domain, frequency domain and root locus analysis are performed. Most of the methods are extensions of the well known continuous domain techniques. Controller design is the main objective of chapter 4, where several different designs for a rigid-body satellite example are presented. The methods illustrated include continuous and digital domain analysis (in the $w^{\prime}$-plane); root locus design in the $z$-domain; state feedback control; digital PID implementation; deadbeat response design; and optimal controllers. All the designs are performed on the same example so that the different controllers can be compared objectively. A brief introduction to sampled-data control systems under noisy conditions is also presented.

Chapter 5 considers the overall hardware and software considerations in real-time computer systems and how such systems can be designed. The important features such as hardware requirements and software aspects that control engineers need to be aware of when constructing a suitable system are presented. Guidance on the co-ordination of the overall system design is also given. In chapter 6 some of the latest developments, namely artificial intelligence, and parallel processing, are discussed. These are likely to have an enormous impact on control applications where the computers will use concepts such as fuzzy logic and other knowledge-based expert systems with appropriate inference engines to think and deduce solutions in a similar fashion as humans do. Such computers will need to possess vast processing power that can only realistically be achieved using parallel processing techniques. Here the computational task can be distributed over a network of processors that can work on sub-tasks and can communicate between each other so that the overall solution can be determined. The majority of computer users at present are experienced only in the traditional sequential "flow diagram" programming approach. The effective programming of parallel computers requires the users to be retrained so that problems such as deadlock, problem partitioning, communication synchronization, computer architecture optimisation and program termination can be solved. These issues are discussed with particular emphasis to transputer systems programmed in occam.

Much of the work described in this book has arisen from lecture courses given by the author to students in the Department of Control Engineering, University of Sheffield as well as to students at Sheffield City Polytechnic and University of Southampton. Constructive comments received from un- 
dergraduate and postgraduate students over the years have improved the material greatly. Also many colleagues have assisted and commented on earlier drafts of some of the chapters. This feedback is gratefully acknowledged and appreciated. In particular the author is grateful to Ian Durkacz, Panos Kourmoulis and Gurmej Virk for their help in preparing sections of the manuscript and diagrams. Dennis Loveday and Joe Cheung proof-read the whole script and made very useful suggestions. In addition the comments made by the series editor Paul Lynn on an earlier draft of the book were invaluable and have been gratefully received to improve the presentation of the manuscript. Finally the author wishes to pay tribute to his wife Ann Marie for her encouragement and understanding over the years. Without her moral and physical assistance this book would never have been accomplished. 